\title{
0 desenvolvimento musical de crianças com Transtorno do Espectro do Autismo em Musicoterapia: revisão de literatura e relato de caso
}

\section{Musical development of children with Autism Spectrum Disorder in Music Therapy: literature review and case report}

\author{
Marina Freire* \\ Universidade Federal de Minas Gerais (UFMG), Brasil \\ marinahf@gmail.com \\ Jéssica Martelli** \\ Universidade Federal de Minas Gerais (UFMG), Brasil \\ jessicamdelforno@ig.com.br
}

\author{
Gabriel Estanislau*** \\ Universidade Federal de Minas Gerais (UFMG), Brasil \\ ggstanis@gmail.com \\ Betânia Parizzi**** \\ Universidade Federal de Minas Gerais (UFMG), Brasil \\ betaniaparizzi@hotmail.com
}

\footnotetext{
* Marina Freire é musicoterapeuta, professora assistente da Escola de Música da Universidade Federal de Minas Gerais (UFMG), Brasil; mestra em Neurociências pelo Instituto de Ciências Biológicas da Universidade Federal de Minas Gerais (UFMG), Brasil; doutoranda do Programa de Pós-Graduação em Música da mesma Universidade.
}

** Jéssica Martelli é graduanda em Licenciatura em Música pela Universidade Federal de Minas Gerais (UFMG), Brasil; bolsista de extensão do Programa Núcleo de Educação Musical e Cultura, voluntária no projeto de Iniciação Científica "Relações entre os efeitos terapêuticos da Musicoterapia Improvisacional e o desenvolvimento musical de crianças com autismo" na mesma instituição.

*** Gabriel Estanislau é bacharel em Música com habilitação em Musicoterapia pela Universidade Federal de Minas Gerais (UFMG), Brasil. Tem formação em Musicoterapia Plurimodal e no Modelo Denver de Intervenção Precoce para Autismo; colaborador voluntário do Laboratório de Extensão em Autismo e Desenvolvimento (LEAD) da Faculdade de Filosofia e Ciências Humanas da Universidade Federal de Minas Gerais (UFMG).

**** Betânia Parizzi é professora associada da Escola de Música da Universidade Federal de Minas Gerais (UFMG), Brasil, com atuação no Programa de Pós-Graduação em Música da mesma instituição. Doutora em Ciências da Saúde - saúde da criança e do adolescente pela Faculdade de Medicina da Universidade Federal de Minas Gerais (UFMG), Brasil. 


\section{Resumo}

O Transtorno do Espectro do Autismo (TEA) é um distúrbio que afeta o desenvolvimento desde a primeira infância. Estudos sobre música e cérebro enfatizam a importância da música para o desenvolvimento humano e ressaltam o papel da música para pessoas com TEA. Devido às importantes relações da música com o desenvolvimento e com o TEA, a Musicoterapia é uma possibilidade terapêutica ascendente para pessoas com esse diagnóstico, como forma de propiciar melhoras na comunicação e na socialização. O presente trabalho visa compreender $O$ desenvolvimento cognitivo-musical de crianças com TEA por meio de uma revisão de literatura sobre o desenvolvimento musical de pessoas com TEA em intervenções musicoterapêuticas e de um relato de caso de uma criança com TEA em sessões de Musicoterapia Improvisacional Musicocentrada. Os resultados apontam para a necessidade de mais estudos sobre o tema e para a importância do desenvolvimento musical no tratamento musicoterapêutico da criança com Transtorno do Espectro do Autismo.

Palavras-chave: Autismo. Transtorno do Espectro do Autismo. Desenvolvimento Musical. Musicoterapia Improvisacional Musicocentrada

\section{Abstract}

Autism Spectrum Disorder (ASD) is a disorder that affects development from an early age. Music and brain studies highlight the importance of music for human development and emphasize the role of music for people with ASD. Given the important relations between music and development, and with ASD, Music Therapy has become a therapy of increasingly potential for people with this diagnosis, as a way to improve communication and socialization. This paper aims to understand children with ASD cognitive-musical development through a literature review on the musical development of people with ASD in Music Therapy interventions, and through a case report of a child with ASD in Music-Centered Improvisational Music Therapy sessions. The results point to the need for further studies on the subject and the importance of musical development in the therapeutic treatment of children with Autism Spectrum Disorder.

Keywords: Autism. Autism Spectrum Disorder. Musical Development. Improvisational Music Centered Music Therapy. 


\section{Introdução}

Nesta seção introdutória abordaremos três assuntos fundamentais para a contextualização teórica deste trabalho: (1) o Transtorno do Espectro do Autismo - TEA, (2) as relações da música com o desenvolvimento humano e (3) a Musicoterapia Improvisacional Musicocentrada.

\section{O Transtorno do Espectro do Autismo}

O autismo, hoje preferencialmente chamado de Transtorno do Espectro do Autismo (TEA) por abranger uma gama de diferentes manifestações clínicas e níveis de gravidade, é um distúrbio do neurodesenvolvimento que apresenta déficits persistentes na comunicação social recíproca/interação social e em interesses, atividades e/ou comportamento com a presença de padrões restritivos e repetitivos. De acordo com o Manual Diagnóstico e Estatístico de Transtornos Mentais (DSM-5), esses sintomas estão presentes desde os primeiros meses de vida, porém costumam ser reconhecidos durante o segundo ano, dependendo de sua gravidade. As características presentes no TEA limitam ou prejudicam o funcionamento diário dos indivíduos com esse distúrbio (APA, 2014).

Diagnosticado quatro vezes mais frequentemente no sexo masculino do que no feminino, o Transtorno do Espectro do Autismo se apresenta em 1\% da população, nos Estados Unidos e em outros países (pesquisas de prevalência ainda não foram publicadas no Brasil). As características comportamentais do TEA tornam-se evidentes na infância, quando a criança demonstra falta de interesse social, porém o estágio em que o prejuízo funcional ficará evidente pode variar de acordo com as características do indivíduo e do seu ambiente (APA, 2014).

Desde que o diagnóstico de autismo foi cunhado por Leo Kanner e Hans Asperger, no início da década de 1940, existem correntes teóricas que tentam compreender a etiologia central desse distúrbio. Atualmente, muitos são os estudiosos que defendem a genética como a principal causa do transtorno. Frith (2008) aponta investigações que eliminam o risco do TEA por contaminação, vacinação e outros agentes ambientais e cita relatos de Hans Asperger que descreviam características do Transtorno do Espectro do Autismo nos pais de algumas crianças com o diagnóstico. Além disso, segundo a autora, a maior probabilidade de homens estarem no espectro do que mulheres indica uma característica genética, assim como estudos com gêmeos univitelinos e bivitelinos, realizados nos anos 1970 e 1980, nos quais os gêmeos idênticos, univitelinos, tinham 90\% de chance de ambos terem TEA, enquanto os não idênticos, bivitelinos, tinham apenas $10 \%$ de chance, indicando que esse transtorno surge mais por características genéticas do que ambientais. Contudo, esses fatos não descartam os outros indicadores do TEA. Um exemplo disto é que, na maioria das vezes em que gêmeos idênticos são ambos diagnosticados, um deles é mais comprometido do que o outro, e somente o fator genético não explicaria essa diferença (FRITH, 2008; SAMPAIO, 2015).

Outra causa defendida para a origem do Transtorno do Espectro do Autismo centra-se na Teoria da Mente, argumentando que o mesmo é derivado de uma disfunção no 
sistema de neurônios-espelho. A ideia dos neurônios-espelho partiu de Rizzolatti (2004 apud FREIRE, 2010), ao identificar em macacos a presença de neurônios que se ativam quando "ações musculares são executadas e quando as mesmas ações são observadas" (RIZZOLATTI, 2004 apud FREIRE, 2010, p.11-12). Esses neurônios, que seriam escassos no TEA, têm como principal característica a imitação imediata ou espelhada de uma atividade, relacionando-os a interações sociais, percepção do outro e empatia (RIZZOLATTI, 2004 apud FREIRE, 2010). O teste de Teoria da Mente demonstra que, no geral, as crianças com TEA possuem uma falsa crença sobre o outro e que esse processo mental é mais difícil de ser adquirido/compreendido do que nas crianças neurotípicas (FRITH, 2008). Sampaio e colaboradores (2015) apontam que as áreas cerebrais supostamente alteradas pelo TEA são o córtex orbitofrontal, lobos temporais e corpo amigdaloide, responsáveis por falhas de mentalização chamadas de cegueira mental, que causam déficits nos aspectos de compreensão emocional da comunicação social, principalmente dificuldades no compartilhamento de sentimentos.

A diversidade fenomenológica e comportamental do Transtorno do Espectro do Autismo, as discussões sobre suas possíveis causas e as diferentes propostas de tratamento motivam a pesquisa em diversos campos do conhecimento, como as neurociências, a saúde, a educação e a música (BERGER, 2003). Novas formas de intervenções terapêuticas e educacionais vêm sendo somadas a intervenções já comprovadas, a fim de aprimorar meios de estimulação das habilidades afetadas pelo TEA e amenizar comportamentos prejudiciais (BERGER, 2003). Crianças com esse diagnóstico demandarão algum tipo de apoio durante suas vidas, e é a gravidade dos déficits na comunicação social e dos padrões restritos ou repetitivos de comportamento que definirá o quanto esta pessoa precisará de ajuda (FRITH, 2008).

A literatura sobre o Transtorno do Espectro do Autismo relata uma intensa relação entre música e pessoas com o TEA, tanto na percepção como na produção musical. Crianças com esse transtorno podem apresentar uma percepção auditiva mais aguçada, principalmente para estímulos sonoros simples e de altura do som, como no ouvido absoluto (OUIMET et al., 2012). Esses indivíduos também se mostram mais motivados ao engajamento interpessoal em uma produção musical, segundo Sampaio e colaboradores (2015), devido aos aspectos não verbais da música.

Wan e Schlaug (2010) justificam a utilização da música em intervenções terapêuticas para o TEA, principalmente para desenvolvimento da linguagem e regulação das emoções, devido ao potencial da música de aumentar conexões entre lobos frontal e temporal, nos dois hemisférios, e de ativar áreas cerebrais associadas às emoções. Indo ao encontro desses autores, Fabricius (2012) ratifica que os componentes sensório-motores e áreas ativadas para linguagem e canto são os mesmos, e acrescenta que os sistemas neurológicos responsáveis pela fala e pelo som são mais requisitados na percepção auditiva de pessoas com TEA do que os sistemas responsáveis apenas pela fala.

Conforme Molnar-Szakacs e Heaton (2012), pessoas com TEA, de modo geral, demonstram notável interesse por música e podem até mesmo ter uma habilidade excepcional na área musical, o que faz da música, segundo os autores, uma janela única para o mundo do Transtorno do Espectro do Autismo. Em estudo anterior, os mesmos 
autores discorrem sobre outra hipótese, a partir de estudos da Psicologia da Música, de que atividades musicais estão intrinsecamente associadas a atividades sociais. Logo, atividades musicais para pessoas com TEA proporcionariam convívio e interação, possibilitando, consequentemente, a aquisição de linguagem e de habilidades motoras (MOLNAR-SZAKCS et al., 2009). Pesquisas como a de Brownell (2002) corroboram esta teoria, demonstrando melhor resposta social de crianças com TEA a canções com comandos do que a comandos falados.

\section{A música e o desenvolvimento humano}

A Psicologia da Música apresenta investigações importantes sobre as relações entre o ser humano e a música no que diz respeito à comunicação social, independentemente de o indivíduo ter uma patologia, como o TEA, ou apresentar um desenvolvimento neurotípico. Trainor e Hannon (2013) explanam que o contato com a música, mesmo que informal, auxilia no desenvolvimento de capacidades não musicais, como as habilidades pró-sociais. Os autores também discorrem sobre a música na infância, enfatizando suas funções sociais, como agrupar e adquirir traços daquela cultura desde a primeira infância, e a presença da comunicação da afetividade através de canções em todos os povos e civilizações, principalmente com bebês.

As descobertas na área das neurociências sobre as relações entre música e cérebro potencializam os fundamentos da Psicologia da Música, apontando a infância como a fase mais oportuna para o desenvolvimento cerebral e de todas as atividades humanas (ILARI, 2006). A autora destaca as quatro fases do desenvolvimento estrutural do cérebro humano: a primeira fase ocorre durante o estágio fetal, que diferencia os seres humanos em homens e mulheres, ou seja, a estrutura básica do cérebro começa a se formar. Estima-se que a segunda fase aconteça logo após o nascimento e percorra os primeiros quatro anos de vida. Nesse estágio ocorrem as sinapses responsáveis pela visão, pela audição, pelo raciocínio lógico e pela linguagem. A terceira fase, que se estabelece entre quatro e dez anos de idade, pode ser considerada um complemento das conexões neurais já existentes no cérebro humano e também a criação de novas conexões. Já a última fase transcorre após os dez anos de idade, quando a organização já se faz inerente ao cérebro, podendo, contudo, haver mudanças resultantes de novos aprendizados (HERCULANO-HOUZEL, 2001 apud ILARI, 2006). Portanto, o cérebro humano é mais flexível no decorrer da infância, e os efeitos da aprendizagem são maiores nesta fase do que em qualquer outra época da vida (FLOHR et al., 2000). Esta capacidade humana de mudar as estruturas e funções do sistema nervoso, chamada neuroplasticidade, estabelece ligação intrínseca com as experiências e padrões de experiências vivenciadas, como as atividades musicais (WAN; SCHLAUG, 2010).

O desenvolvimento cognitivo-musical é um dos importantes parâmetros que atestam a neuroplasticidade na infância, pois, quanto mais a criança aprende, mais ela consegue aprender (TRAINOR; HANNON, 2013). Desde a primeira infância o desenvolvimento auditivo se mostra evidente no gradual aprimoramento de localização das fontes sonoras e de reconhecimento de alturas, timbres e intensidades, e é também nesta fase que as crianças começam a apresentar suas preferências musicais (WERNER; VANDENBOS, 1993 
apud ILARI, 2006). De acordo com Sacks (2007), os padrões que auxiliam a memória, presentes nas rimas, métricas e canto, são os meios mais poderosos para a eficácia da retenção e memorização da mente e se encontram em todas as culturas.

A música e a linguagem se misturam no início da vida, tornando-se independentes com o passar do desenvolvimento infantil e separam-se quando a criança aprende a distinguir o canto da fala. ${ }^{1}$ Pesquisas como a de Rocha e Boggio (2013) evidenciam a natureza multifocal dos estímulos musicais, indicando semelhanças entre música e linguagem principalmente para o cérebro das crianças. $O$ desenvolvimento cognitivo-musical neste estágio está normalmente associado às funções psicossociais de imitação, comunicação e emoção entre crianças e adultos (ILARI, 2006; TRAINOR; HANNON, 2013).

Os processos de imitação em música podem estar relacionados com os neurônios-espelho, já explicados no início deste trabalho, que, por sua vez, estão associados à ação e à observação de um outro indivíduo (ROCHA; BOGGIO, 2013). O sistema humano de neurônios-espelho pode se ativar em situações musicais, como em ações motoras instigadas pela previsibilidade de uma frase musical e na troca de experiências entre músicos e ouvintes (MOLNAR-SZAKACS et al., 2009).

Os processos de comunicação e emoção se correlacionam em música, partindo da assimilação dos efeitos da música na experiência estética (FIGUEIRA, 2015). Para Gerling e Santos (2015), as emoções breves e intensas se transformam na experiência musical, seja tocando/cantando (experiências ativas), seja ouvindo (experiências receptivas). Juslin e Sloboda (2001) apresentam uma definição de emoção em música:

Emoções são respostas relativamente breves, intensas e rapidamente mutantes a eventos potencialmente importantes (oportunidades ou desafios subjetivos) em um meio externo ou interno, usualmente de natureza social, e que envolvem um número de subcomponentes (mudanças cognitivas, sentimentos subjetivos, comportamento expressivo, e tendência de ação) que são mais ou menos sincronizados durante o episódio da emoção. (JUSLIN; SLOBODA, 2013 apud GERLING; SANTOS, 2015, p.15).

Kratus (1993) sugere que a interpretação de emoção na música se fortaleça por volta dos seis anos de idade. Esse estudo analisou crianças de ambos os gêneros com idade de seis a doze anos e foi percebido que elas identificam melhor as emoções alegres e tristes, pois a competência de interpretação se deve à atividade rítmica e à métrica da música.

Antes mesmo da interpretação das emoções que a música pode evocar, ela já está ligada ao afeto das relações interpessoais. Bebês dão sinais de compreensão da musicalidade presente na fala evidenciada pela interação afetiva entre cuidador e bebê (TRAINOR; HANNON, 2013). Partindo da premissa da musicalidade inata, Malloch (1999) e Trevarthen (1999) tecem o conceito de musicalidade comunicativa, "uma habilidade instintiva e universal que se ativa ao nascimento, vital para a comunicação entre as pessoas", caracterizada pela capacidade de combinar qualidades musicais do som, como o ritmo e os gestos sonoros, com movimentos corporais e expressões faciais (MALLOCH, 1999, p.30). Segundo os autores, a musicalidade comunicativa abrange três 
particularidades: o pulso, que se encontra de forma contínua e constante no tempo; a qualidade, que consiste na melodia e nas variações timbrísticas; e as narrativas, que são construídas a partir do pulso e da qualidade (MENDONÇA, 2015).

Segundo Maffioletti (2017), a voz humana cria diferentes formas de entonações seguindo padrões rítmicos, improvisações e imitações, cujo significado é partilhado espontaneamente. A capacidade adquirida nas primeiras semanas de vida e na interação social seguem por toda a vida, pois a música, a cultura e a linguagem se tornam um meio efetivo de comunicação e de expressão (AVILA, 2016).

A musicalidade comunicativa permite condições suficientes de interação entre as mães e os bebês, facilita a habilidade de comunicação social e possibilita um complemento de identidade sonora, pois são nas interações entre os bebês e seus pares que as expressões vocais e corporais acontecem e se estruturam, dando formas aos motivos e intenções (AVILA, 2016). Cada cultura propicia a interação e a troca de experiências entre os indivíduos, fazendo com que as expressões de arte e de afeto sejam consolidadas (MALLOCH, 1999).

Assim, a musicalidade, postulada como um traço natural do ser humano, torna-se extremamente relevante para a comunicação interpessoal e para o desenvolvimento humano (QUEIROZ, 2003). Uma vez que a música é um modo de entender o mundo e nossas experiências nele, experimentando a afetividade e o saber através de emoções (SWANWICK, 1979), a musicalidade propicia ao ser humano a capacidade de perceber pontos dinâmicos de uma experiência, vivenciar a integração entre o mundo interno e o mundo externo, através do "alargamento da percepção de si mesmo", e abrir-se à percepção da unicidade (QUEIROZ, 2003, p.19).

A musicalidade concede a percepção de uma dimensão em que coisas e pessoas e condições se integram, aquela dimensão existencial na qual interagem dinamicamente, isto é, a dimensão da harmonia ou da proporção dinâmica entre as partes de um todo. (QUEIROZ, 2003, p.23).

\section{A Musicoterapia Improvisacional Musicocentrada}

A Musicoterapia, utilização profissional do som e seus elementos para fins terapêuticos (WFMT, 2011), entende a musicalidade inata como reflexo da sensibilidade universal à música e seus muitos componentes, estando presente em todo indivíduo, independentemente de desafios, atrasos e deficiências que ele possa apresentar (KIRKLAND, 2013). Nordoff e Robbins (2007), dois dos pioneiros da Musicoterapia mundial, levantam a importância da musicalidade ao formularem o conceito de music child (em tradução livre para o português, poderia significar "criança musical"), que representa o objetivo último do processo terapêutico: o desenvolvimento integral da criança, o potencial de plena saúde que se encontra velado na pessoa com deficiência e que só é possível de ser atingido através do resgate da musicalidade individual inata.

O modelo musicoterapêutico centrado na música do paciente de Nordoff e Robbins deu origem à abordagem atualmente denominada Musicoterapia Improvisacional Musicocentrada. Esses autores (1975) partiram de experiências de improvisação musical com 
crianças com autismo, individualizando atividades musicais conjuntas de acordo com as demandas e os potenciais de cada um. Os autores ressaltam a importância de levar o paciente a uma experiência coativa prazerosa através da música, auxiliando-o a desenvolver sua musicalidade e sua expressividade, ampliando sua comunicabilidade musical e fortalecendo suas relações interpessoais. Assim, para a abordagem de Musicoterapia Improvisacional Musicocentrada, mesmo que a musicalidade do indivíduo esteja em sua forma latente, ela é peça fundamental para auxiliar seu desenvolvimento e recuperação. Por isso, ajudar a desenvolver a expressão da musicalidade de crianças com transtornos patológicos é a principal maneira de propiciar o desenvolvimento integral dessas crianças (NORDOFF; ROBBINS, 2007).

Trabalhando com a criança com Transtorno do Espectro do Autismo de forma ativa, a Musicoterapia Improvisacional Musicocentrada busca motivar o engajamento na experiência musical conjunta, estimulando o manuseio de instrumentos, a utilização do corpo e da voz e o diálogo musical, visando, assim, ao desenvolvimento de comunicação e interação (BRUSCIA, 1987). De acordo com Brandalise (2001), um dos objetivos principais da abordagem de Musicoterapia Musicocentrada é a detecção dos Fragmentos de Tema Clínico e do Tema Clínico. Os Fragmentos de Tema Clínico são qualquer potencial musical trazido pelo paciente: por exemplo, o trecho de uma música que a pessoa está cantando, um som que a pessoa faz ao tocar algum instrumento (mesmo que ainda a nível exploratório), o ritmo de sua respiração, o ritmo do andar ou correr, a melodia do choro, entre outros. A função do musicoterapeuta é trazer esses fragmentos sonoros (reais ou potenciais) para o nível musical, através principalmente da improvisação, auxiliando o paciente a encontrar o seu Tema Clínico. A importância da utilização dos Fragmentos de Temas Clínicos está no fato de trazer para a música elementos próprios do paciente, da musicalidade do paciente, alcançando a individualização musical apregoada por Nordoff e Robbins. Assim, o paciente se sente acolhido e mais motivado a se engajar na experiência musical, o que se faz ainda mais necessário no caso de crianças com TEA, que podem apresentar dificuldades na iniciativa de interação e no estabelecimento de vínculo com o musicoterapeuta (BRANDALISE, 2001; NORDOFF; ROBBINS, 2007).

Autores da abordagem musicocentrada de Musicoterapia Improvisacional, como Brandalise (2001) e Nordoffe Robbins (2007), concordam que a Musicoterapia proporciona à criança com Transtorno do Espectro do Autismo o desenvolvimento de sua musicalidade e de sua comunicabilidade musical. Contudo, não especificam o desenvolvimento de habilidades musicais neste contexto, nem como causa nem como efeito daquele desenvolvimento. $O$ foco das práticas e pesquisas em Musicoterapia e TEA, inclusive nas intervenções improvisacionais musicocentradas, são os avanços terapêuticos (não musicais) adquiridos pela criança (WIGRAM; GOLD, 2006). De fato, os ganhos cognitivos, comunicacionais e sociais da criança com TEA que passa por tratamento de Musicoterapia Improvisacional já são inegáveis na literatura científica atual (WIGRAM; GOLD, 2006; KIM et al., 2008; KIM et al., 2009; GATTINO, 2012; SARAPA; KATUSIC, 2012; THOMPSON et al., 2013, FREIRE, 2014).

Contudo, esses ganhos terapêuticos poderiam se relacionar com o desenvolvimento musical da criança, adquirido durante as experiências musicais em Musicoterapia? É possível avaliar o desenvolvimento musical de crianças com TEA dentro das sessões musico- 
terapêuticas? E, em caso positivo, esse desenvolvimento musical influencia as melhoras da criança? O presente artigo é um dos primeiros estudos do grupo de pesquisa destes autores, que buscam responder a essas questões, com o objetivo de compreender os processos de desenvolvimento cognitivo-musical de crianças com Transtorno do Espectro do Autismo que recebem tratamento em Musicoterapia Improvisacional Musicocentrada. A escolha da abordagem musicoterapêutica utilizada se dá, além da identificação pessoal dos musicoterapeutas envolvidos, por ser a abordagem teórica de Musicoterapia que mais se aproxima da compreensão da relação da musicalidade com o processo musicoterapêutico. Este trabalho, ao tratar do desenvolvimento musical, se dirige, pois, às interfaces da Musicoterapia ao escolhê-la como método de intervenção com a Educação Musical, visando a contribuições para as duas áreas, bem como para a área da saúde como um todo, na busca por contribuir com uma melhor qualidade de vida para crianças com TEA.

\section{METODOLOGIA}

Este trabalho apresenta nos próximos itens uma revisão de literatura sobre o desenvolvimento musical de pessoas com Transtorno do Espectro do Autismo e um relato de caso em Musicoterapia Improvisacional Musicocentrada com uma criança com esse diagnóstico.

Para a revisão de literatura, optamos por uma investigação sistemática de artigos científicos que tratassem do desenvolvimento musical de indivíduos com TEA que passaram por algum tipo de intervenção em Musicoterapia. A busca foi realizada em janeiro de 2018 nas plataformas virtuais Capes e Google Acadêmico. Os termos utilizados na busca em português foram "Musicoterapia", "autismo" e "desenvolvimento musical". Em inglês, foram buscados os termos correspondentes: "Music Therapy", "autism" e "music development" ou "musical development". Os termos poderiam estar em qualquer parte do artigo. Além das duas línguas selecionadas para os termos procurados, também foram incluídos nos resultados artigos que pudessem retornar da busca em espanhol. Devido à já sabida escassez de estudos diretamente relacionados ao tema, não foi estabelecido nenhum intervalo para datas de publicação. Os artigos encontrados foram selecionados primeiramente por seu título e resumo e, quando necessário, pela leitura integral do trabalho.

No relato de caso, apresentamos os trechos mais significativos de um processo musicoterapêutico de uma criança com TEA e os principais aspectos de desenvolvimento da criança observados com o tratamento. Esse tratamento foi realizado no Ambulatório de Autismo do serviço de Psiquiatria Infantil do Hospital das Clínicas da Universidade Federal de Minas Gerais (UFMG) e fez parte da pesquisa de mestrado "Efeitos da Musicoterapia Improvisacional no Tratamento de Crianças com TEA" (FREIRE, 2014), realizada no programa de Pós-Graduação em Neurociências da UFMG. A pesquisa teve aprovação do Comitê de Ética em Pesquisa com Seres Humanos (CAAE: 03655112.3.0000.5149). Os pais do paciente assinaram o Termo de Consentimento Livre e Esclarecido autorizando os atendimentos e a divulgação dos dados para fins científicos. O nome do paciente foi alterado para a preservação do sigilo em pesquisa.

A fim de evidenciar o desenvolvimento musical da criança observada, comparamo-lo aos avanços observados nas áreas de comunicação e sociabilidade através da escala 
Autism Treatment Evaluation Checklist (ATEC) (RIMLAND; EDELSON, 2007). Esta escala, desenvolvida especificamente para avaliar a efetividade de tratamentos para pessoas com Transtorno do Espectro do Autismo, é um instrumento de mensuração inversamente proporcional à melhora do indivíduo, dividida em quatro subescalas que abrangem todas as áreas afetadas pelo TEA: (1) fala/linguagem/comunicação, (2) sociabilidade, (3) percepção sensorial/cognição e (4) aspectos físicos/saúde/comportamento. O ATEC foi respondido pela mãe do paciente no início e no final do tratamento musicoterapêutico.

A análise do desenvolvimento musical da criança foi feita por meio da observação dos vídeos das duas primeiras e das duas últimas sessões, por dois dos presentes autores, utilizando a Escala de Desenvolvimento Musical para Crianças com TEA, desenvolvida para esta pesquisa a partir da Tabela de Avaliação do Desenvolvimento Musical de Crianças Portadoras de TEA criada por Oliveira (2015). Os comportamentos musicais observados por meio desta escala são: (1) percepção/exploração rítmica, (2) percepção/exploração sonora e (3) exploração vocal. Também são observados nesta escala os comportamentos restritivos, a socialização, a cognição e a movimentação corporal durante as intervenções musicoterapêuticas, pois, como discutido na introdução deste trabalho, esses comportamentos relacionam-se diretamente ao processo de desenvolvimento musical das crianças. Todos os itens desta escala são classificados em ausentes, pouco ou muito presentes, e apenas a parte de comportamentos restritivos é pontuada de forma inversa, gerando uma mensuração diretamente proporcional ao desenvolvimento musical do paciente.

\section{REVISÃO DE LITERATURA}

As buscas da revisão de literatura geraram 165 resultados, sendo 57 para as buscas com termos em português e 108 para as buscas com termos em inglês. Na primeira etapa da seleção foram eliminadas 59 publicações, pelos seguintes motivos:

- três artigos não estavam disponíveis para acesso on-line através do link fornecido pela plataforma de busca,

- cinco artigos não estavam nas línguas incluídas na revisão (português, inglês ou espanhol),

- oito publicações eram duplicatas (artigos repetidos),

- 21 resultados não se tratavam de artigos científicos, mas sim de livros ou websites,

- 22 eram resultados remanescentes que não tinham nenhuma relação com os termos da busca.

Entre os 106 artigos restantes, que foram estudados mais detalhadamente, apenas três se encaixavam nos critérios de inclusão da revisão. Os outros 103 artigos foram excluídos pelos seguintes motivos:

- Não envolviam pessoas com TEA (23 artigos). Essas publicações discorriam sobre Musicoterapia com outras populações, como pessoas com deficiências sensoriais, Síndrome de Down e Transtorno de Déficit de Atenção e Hiperatividade. Não foram analisados os métodos utilizados para intervenção musicoterapêutica e avaliações para saber se algum estudo envolvia a avaliação do desenvolvimento musical dessas 
pessoas. Muitos desses artigos citavam achados sobre a eficácia da Musicoterapia no atendimento a crianças com Transtorno do Espectro do Autismo como fundamentação para a possível eficácia da Musicoterapia em outras populações.

- Não envolviam intervenções musicoterapêuticas (50 artigos). Essas publicações consistiam em estudos teóricos ou experimentais de outras áreas, como a Psicologia, as Neurociências, a Educação Musical e a Educação Especial, e muitos deles apontavam exemplos dos efeitos da música e da Musicoterapia para pessoas com TEA.

- Não tratavam de desenvolvimento musical (30 artigos). Essas publicações eram estudos experimentais da área de Musicoterapia que avaliavam os efeitos do tratamento musicoterapêutico em pessoas com TEA, porém, sem avaliar desenvolvimento musical. Algumas delas citavam o desenvolvimento musical, principalmente na introdução, levantando-o como um possível fator a ser observado em Musicoterapia, mas sem aprofundar neste tópico. Vale ressaltar que as avaliações dos efeitos das intervenções investigadas, mesmo em modelos diferentes de Musicoterapia, demonstravam melhoras dos pacientes com TEA principalmente em relação à comunicação e à socialização.

Em relação aos três artigos incluídos, um estava em inglês e dois em português. $O$ artigo em inglês investiga os efeitos da Musicoterapia em estudo experimental (BOSO et al., 2007). Os dois artigos em português são mais recentes e ambos consistem em projetos de pesquisa em andamento que envolvem a Musicoterapia e a Educação Musical (FREIRE; PARIZZI, 2015; SANTOS, 2015).

Boso e colaboradores (2007) avaliaram a evolução de comportamentos autísticos e de habilidades musicais de oito adultos com TEA severo que passaram por sessões grupais de Musicoterapia Interativa. Foram realizadas 52 sessões semanais de 60 minutos cada, em processo de longa duração, o que aproxima a pesquisa à realidade clínica musicoterapêutica. Os oito pacientes foram atendidos juntos em todas as sessões. Os pesquisadores avaliaram a evolução de aspectos clínicos do TEA (comportamento e socialização) e de habilidades musicais dos participantes: percepção musical, cantar pequenas melodias, tocar a escala de Dó maior no teclado, reproduzir ritmos e executar células rítmicas complexas. As avaliações foram quantitativas, e as medições foram coletadas individualmente no início (T1), no meio (T2) e no fim do tratamento (T3), utilizando as escalas Clinical Global Impressions-Severity (CGI-S), Clinical Global Impressions-Improvement (CGI-I), Brief Psychiatric Rating Scale (BPRS) e escalas desenvolvidas pelos próprios autores especificamente para avaliação de habilidades musicais. Os autores não publicaram a escala utilizada nem explicam como a escala foi desenvolvida, explicando apenas que foram dadas pontuações de 1 a 7 ou 1 a 5 para as habilidades avaliadas, através de observações na avaliação inicial (T1) e durante as sessões (T2 e T3). Os resultados mostraram mudanças significativas em todos aspectos avaliados, principalmente entre o início e o meio do tratamento. As implicações deste estudo são: a possível conexão entre habilidades musicais e ganhos clínicos, a não necessidade de pesquisas tão longas (pois resultados significativos foram encontrados com metade do tempo de tratamento) e o fato de a Musicoterapia poder ser considerada eficaz no tratamento de adultos com TEA.

Santos (2015) apresenta o projeto de extensão “Desenvolvimento de habilidades musicais em crianças com autismo", parte empírica de investigação do doutoramento 
da autora que relata o seu processo de implementação (elaboração, chamada de público, chamada de estagiários). Participam do projeto 20 crianças com Transtornos do Espectro do Autismo, com a faixa etária de 6 a 14 anos, três estagiários das áreas de Musicoterapia, Psicologia e Educação Musical e a pesquisadora. Os estagiários foram escolhidos por serem considerados compatíveis com os objetivos do projeto, todos eles (uma musicoterapeuta, um psicólogo, que também é músico, e uma educadora musical com formação em enfermagem) apresentando alguma relação com a música e experiências prévias com crianças com TEA. Os atendimentos em grupos de duas, três ou quatro crianças, com 50 minutos de duração, acontecem uma vez por semana e não têm custos para os seus participantes. Os grupos foram definidos pela faixa etária e pelo nível de severidade das crianças. Partindo de uma escuta ativa, onde a criança indica o caminho musical e a pesquisadora a segue, proporcionando expansões e outras propostas/atividades, os atendimentos se baseiam nas metodologias ativas da Educação Musical (MATEIRO; ILARI, 2011 apud SANTOS, 2015) e nos métodos da Musicoterapia, como a improvisação e a recriação musicais (BRUSCIA, 2000 apud SANTOS, 2015).

O trabalho de Santos tem como intuito identificar as habilidades musicais das crianças atendidas, e, para isso, foi criada uma ficha de identificação das habilidades musicais, pensada para ser um instrumento auxiliar da observação participante sistemática dos envolvidos. Esse instrumento de avaliação não foi divulgado no artigo, porém a autora o descreve organizando as habilidades musicais por níveis de complexidade, em que o primeiro nível seria constatar se a criança reage ao estímulo sonoro, e o último nível a improvisação e/ou composição. Outras formas de coletas e análises de dados foram a filmagem por vídeos e o diário de campo, onde a autora registra suas impressões e sentimentos em relação aos atendimentos. Além do desenvolvimento musical dos sujeitos, o trabalho visa alcançar objetivos relativos à melhora da interação social e da comunicação dos mesmos. O desenvolvimento musical é tomado como uma ação fundamental para a elaboração de estratégias que contribuirão com o desenvolvimento global dos participantes. Neste trabalho, a autora destaca também a musicalidade das pessoas com TEA como fator motivacional para a realização do seu projeto. Nos seus dizeres:

[...] a música os afeta e com isso cria uma ponte com o mundo a sua volta. Eles saem do seu isolamento para olhar na direção do estímulo sonoro/musical e muitos são capazes de compartilhar a experiência musical, tocando ou cantando, apesar das dificuldades apresentadas nos domínios de comunicação e interação. Alguns apresentam uma facilidade impressionante para reproduzir melodias, cantando ou tocando instrumentos. Outros, aqueles que têm severas dificuldades de interação e de comunicação, costumam ter uma reação corporal ao estímulo sonoro/musical e demonstram, dessa forma, o quanto são afetados pela música. A música e o som os atingem diretamente, sem defesa. (SANTOS, 2015, p.75-76).

O último artigo encontrado (FREIRE; PARIZZI, 2015) pertence ao grupo de pesquisa do presente trabalho e explana um projeto de pesquisa que visa investigar o desenvolvimento musical de 20 crianças com TEA, entre 3 e 6 anos de idade, que já passaram por tratamento de Musicoterapia na abordagem Improvisacional Musicocentrada e as possíveis relações 
desse desenvolvimento com os ganhos terapêuticos encontrados, a fim de evidenciar a influência do desenvolvimento musical no desenvolvimento global de crianças com TEA. A pesquisa propõe a validação de uma escala para avaliação do desenvolvimento musical de crianças com esse transtorno, a fim de possibilitar uma investigação quantitativa através da análise de vídeos das sessões musicoterapêuticas, por avaliadores externos (musicoterapeutas e educadores musicais experientes na área do autismo). Segundo os autores, a Musicoterapia Improvisacional é uma forma de tratamento bastante utilizada em crianças com TEA e emprega as técnicas da improvisação musical clínica para desenvolver vínculo, expressão e musicalidade. Freire e Parizzi (2015) apontam como meta do estudo a interseção entre as áreas da Musicoterapia e da Educação Musical, ao levar em consideração que ambas trabalham com o desenvolvimento da musicalidade, visando a contribuições para as duas áreas.

Esta revisão de literatura mostra um número pequeno de artigos, publicados recentemente (sendo dois deles pesquisas em andamento), e que se diferenciam pelos métodos de avaliação e aplicação da Musicoterapia e faixa etária do público atendido. Os resultados indicam que, apesar de haver muitas possíveis interseções entre a Musicoterapia e o desenvolvimento musical de crianças com TEA, o aprofundamento neste tema é ainda incipiente. Mesmo que teóricos da Musicoterapia citem a musicalidade como fundamental para o processo terapêutico e que pesquisas comprovem a eficácia do tratamento musicoterapêutico de pessoas com TEA, não são exploradas as relações entre a terapia e o modo com que os pacientes se desenvolvem musicalmente, nem como causa das evoluções nem como efeitos do tratamento. Assim, ainda que a Musicoterapia seja levantada como fundamentação para as importantes relações entre música e TEA, e, de modo inverso, mesmo que as relações entre música e TEA fundamentem a ascensão da Musicoterapia como campo de pesquisa e prática, a área ainda não explorou os importantes significados do desenvolvimento musical para a sua prática clínica e sua eficácia.

As publicações encontradas oferecem interfaces entre áreas distintas, sendo elas Musicoterapia e Medicina ou Musicoterapia e Educação Musical. Essa interação evidenciada por todos os autores faz-se importante para o avanço de temas interdisciplinares, pois, conforme afirmam Chagas e Pedro (2008), leva a discussões de métodos, conceitos e estruturas das áreas envolvidas, trazendo complementaridade e aprimoramento para todas elas, e, consequentemente, para a ciência e para o próprio pensamento humano.

\section{RELATO DE CASO}

Para exemplificar os tópicos levantados no presente trabalho, os autores selecionaram um relato do processo musicoterapêutico de 15 sessões de uma criança com diagnóstico de TEA. As sessões de Musicoterapia foram fundamentadas nos referenciais teóricos sobre o desenvolvimento de crianças com TEA e na abordagem Improvisacional Musicocentrada, apresentados na introdução deste artigo. Seguindo essa abordagem, as intervenções musicoterapêuticas realizadas buscavam motivar a criança à exploração dos instrumentos musicais e da voz por meio da experiência coativa de improvisação musical, lúdica e prazerosa, sempre com o objetivo de fortalecer o vínculo terapêutico e 
desenvolver musicalidade e expressividade, estimulando, assim, comunicação e interação, que são as áreas mais afetadas no TEA e, portanto, as que mais precisam ser trabalhadas (NORDOFF; ROBBINS, 2007; WIGRAM; GOLD, 2006).

As sessões eram individuais, semanais e tinham 30 minutos de duração cada. Foram utilizados os seguintes instrumentos musicais: a voz humana, um violão, um teclado de quatro oitavas, dois tambores médios (frame drums), duas baquetas, duas maracas, seis ovos de cores sortidas, um reco-reco em forma de sapo e uma flauta doce soprano.

O paciente aqui estudado será chamado pelo nome fictício de Cadu. Na época em que foi encaminhado para a Musicoterapia, Cadu tinha 4 anos e meio de idade. Ele havia recebido o diagnóstico de TEA aos 3 anos de idade, e desde então era acompanhado por psiquiatra, fonoaudióloga e terapeuta ocupacional. Suas maiores dificuldades, relatadas pela mãe e pelo psiquiatra responsável pelo encaminhamento, eram: atraso de fala (não falava nenhuma palavra, apenas balbucios e monossílabas) e a presença de movimentos estereotipados com as mãos (chamados hand flappings). De modo geral, Cadu demonstrava pouca interação e pouca intenção comunicativa, precisando de muitos estímulos por parte do adulto para responder a qualquer interação, além de ser mais apegado à mãe do que o esperado para crianças de sua idade. Além disso, nas sessões musicoterapêuticas de avaliação, a criança mostrava-se apática, caracterizando-se por sua passividade diante dos instrumentos musicais e das tentativas de interação da musicoterapeuta.

As três primeiras sessões de Cadu foram marcadas principalmente por seus movimentos giratórios com o tambor de aro. Esta era uma forma estereotipada de utilização do instrumento, girando-o no ar como se fosse um volante, mais do que o tocando. Houve pouca exploração sonora e pouca interação com a musicoterapeuta, que, a todo o momento, convidava o paciente para tocar, buscando atenção compartilhada e o contato visual da criança. Algumas vezes Cadu explorava os sons do tambor e do teclado (utilizando este como um instrumento rítmico), com notas rápidas em trechos intermitentes, demonstrando batidas fortes e compulsivas, sem estabelecer pulsação fixa.

Em poucas vezes, de modo fugaz, Cadu também emitia sons com a voz: as vocalizações "uô" e "ei", o balbucio "br" e a sílaba canônica "pá", na maioria das vezes com altura definida. Suas expressões musicais fragmentadas (Fragmentos de Tema Clínico) podem ser observadas nas Fig. 1 e 2. A musicoterapeuta imitava essas expressões vocais e as inseria em pequenas frases musicais improvisadas no teclado ou no violão, alternando a vocalização "ei" com a sílaba "hei", a fim de incentivar Cadu a emitir novas sílabas. Houve momentos em que a musicoterapeuta também entoava o nome de Cadu na mesma altura e com o mesmo caráter musical de suas vocalizações (Fig. 3).

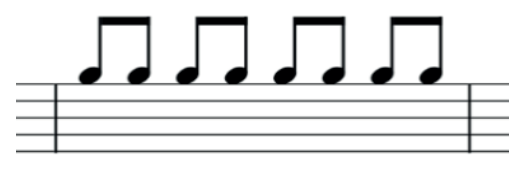

Fig. 1 - Batidas fortes e compulsivas de Cadu (sem compasso definido) 


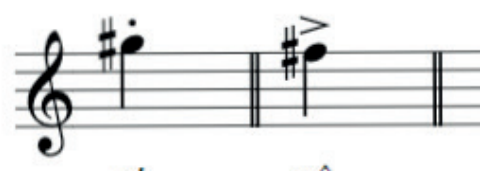

ei uô

Fig. 2 - Exemplos de expressões vocais de Cadu (ei - uô)

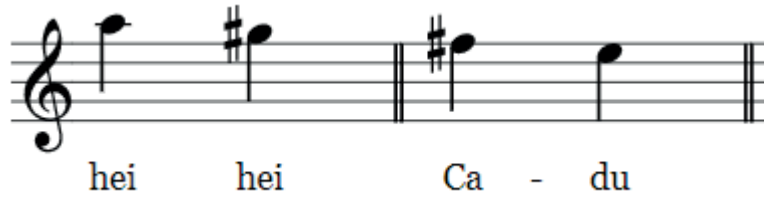

Fig. 3 - Exemplo de espelhamento musical feito pela musicoterapeuta

Na quarta sessão, o paciente demonstrou maior intenção em explorar os sons, começando a se engajar no fazer musical conjunto. Quando a musicoterapeuta começou a acompanhar suas batidas com o violão, elas foram ganhando a marcação de um pulso. Neste momento, as batidas sonoras da criança foram transformadas em uma célula rítmica quaternária (quatro colcheias, uma semínima e uma pausa de semínima), que foi tocada repetidamente por ele (Fig. 4).

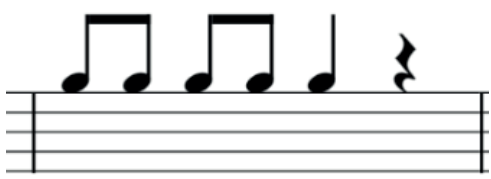

Fig. 4 - Célula rítmica definida por Cadu durante as improvisações conjuntas

Cadu começou a vocalizar a sílaba "pá", seguindo a estrutura rítmica criada (uma sílaba "pá" para cada figura rítmica). A musicoterapeuta dava suporte à sua expressão musical harmonizando power chords ${ }^{2}$ em segundas maiores descendentes no violão (Fig. 5) e cantando junto com célula rítmica estabelecida: ora a sílaba "pá", ora uma descrição do que a criança estava fazendo, a fim de incentivar que a criança continuasse tocando e cantando.

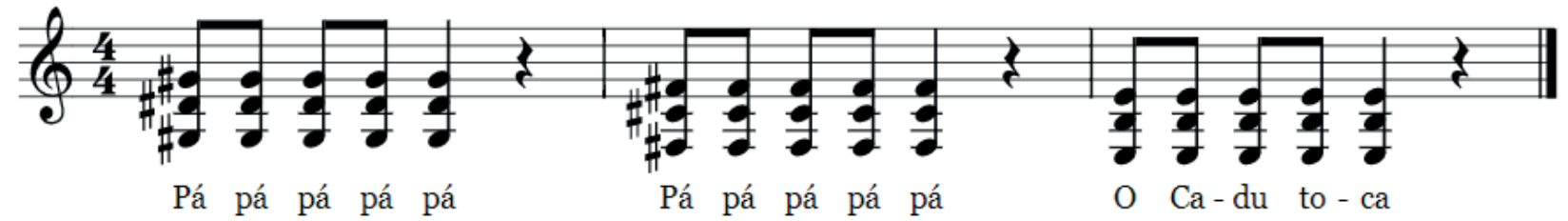

Fig. 5 - Acompanhamento harmônico da musicoterapeuta para a célula rítmica de Cadu

Por vezes, a musicoterapeuta também deixava algumas pausas no canto para estimular respostas vocais do paciente, criando um momento na improvisação musical em que a musicoterapeuta canta e o paciente repete, como um pequeno jogo de imitação ou eco. Esse fazer musical conjunto, aqui constituído pela célula rítmica de Cadu e pelas 
sustentações musicais da musicoterapeuta, deu origem à "Canção do Pá-pá-pá", que passou a ser o Tema Clínico de Cadu nas sessões de Musicoterapia, podendo ser visto na Fig. 6.

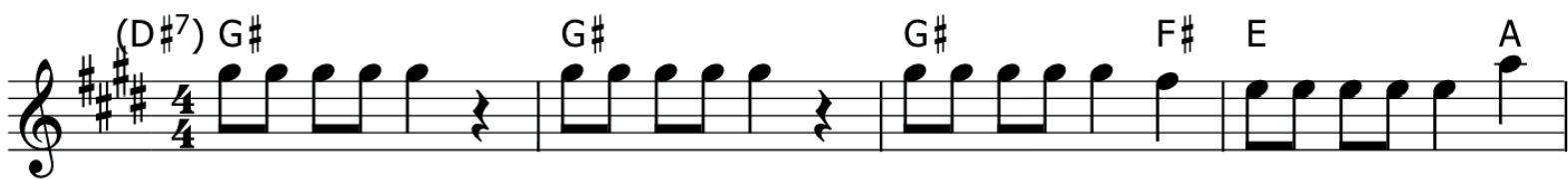

O Ca-du to-ca

O Ca-du to-ca

O Ca-du to-ca a

mú-si-ca do Pá Hei!
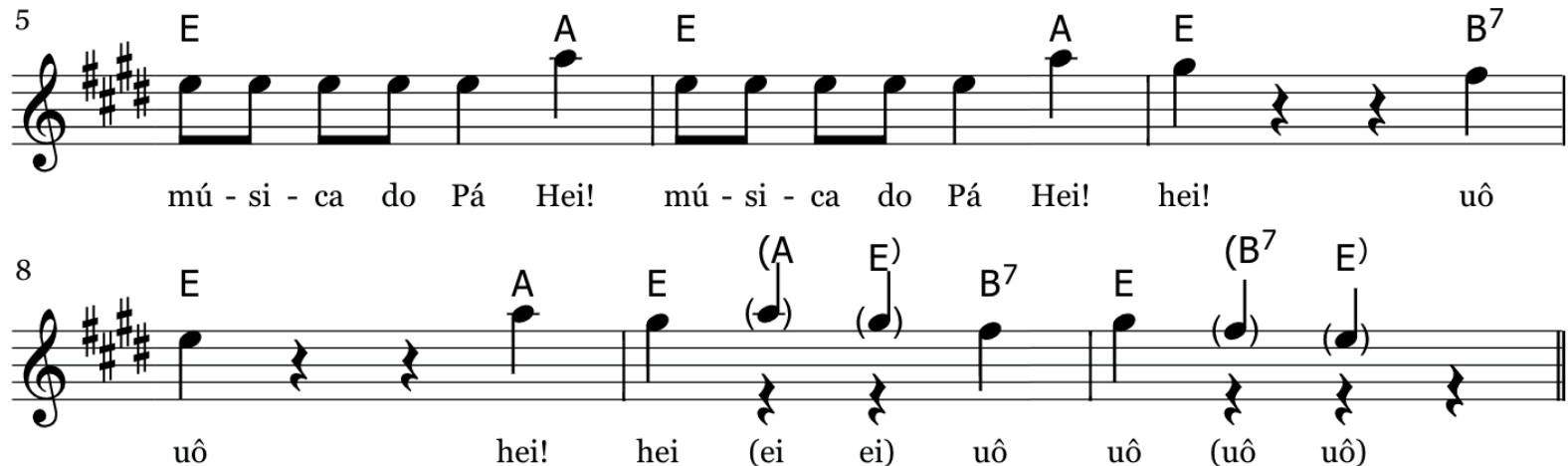

uô

hei! hei $(\mathrm{ei}$

ei)

A $\quad E$

D

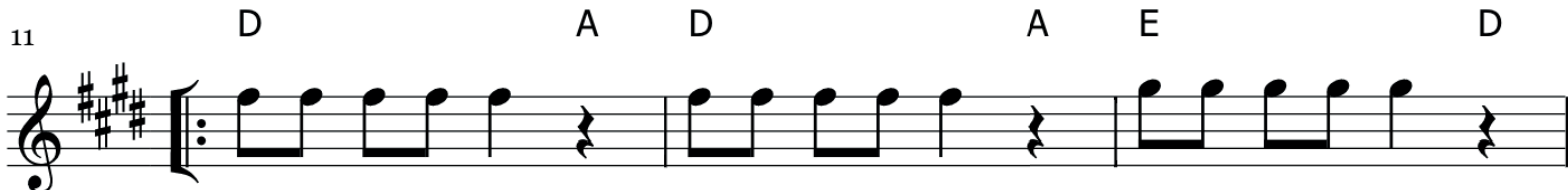

pa pa pa pa Pá

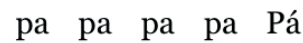

pa pa pa pa Pá

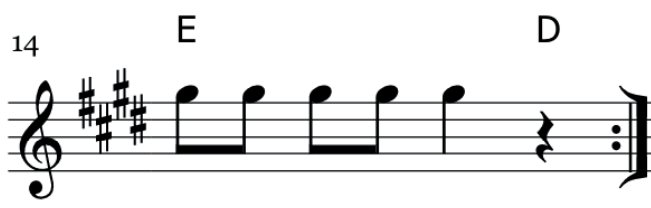

E

pa pa pa pa Pá

pa pa pa pa pa pa pa pa Pá...

Fig. 6 - A "Canção do Pá-pá-pá" criada pela musicoterapeuta e por Cadu. As notas musicais sobrepostas a pausas (compassos 7 a 10) retratam o canto do paciente sobreposto às pausas da musicoterapeuta.

A sessão seguinte começou com Cadu tocando o tambor com a célula rítmica da sessão anterior e cantando "pá-pá-pá". Assim, ficou claro para a musicoterapeuta que ele se lembrava do Tema Clínico e pedia sua ajuda para retornar a ele, sugerindo que tenha gostado da experiência musical coativa. O Tema Clínico foi retomado e acompanhado corretamente pelo paciente no tambor com baquetas, ora tocando a célula rítmica, ora tocando o pulso.

Com o engajamento de Cadu nessas experiências, a musicoterapeuta pôde ajudar a criança a explorar mais as suas possibilidades musicais, propondo variações de sílabas cantadas. Até aquela sessão, a criança só havia emitido a sílaba "pá". A partir de então, imitando a musicoterapeuta, foram cantadas também as sílabas "ká", "há", "má" e "lá" (Fig. 7). De fato, confirmado pela mãe e pela fonoaudióloga do paciente após a sessão, foi a primeira vez que Cadu conseguiu pronunciar a consoante "L". Na sexta sessão, a musicoterapeuta propôs ainda a variação das vogais conjugadas às consoantes que Cadu já sabia falar, por exemplo, "pá, pé, pi, pó, pu". Em seguida, a partir da sessão 7, foi 
possível incentivá-lo a cantar duas sílabas, que depois se transformaram em palavras com significado: "pa-pai", "ma-mãe", "vo-vó", "bi-bi", "Ca-du".

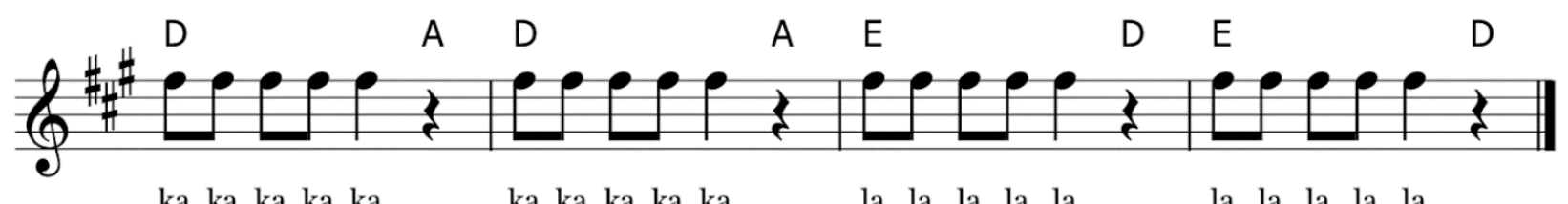

Fig. 7 - Exemplo de variação do Tema Clínico proposta pela musicoterapeuta

Nas sessões seguintes, até o final do processo musicoterapêutico, Cadu explorou o Tema Clínico e variações com os outros instrumentos musicais da sala, inclusive às vezes tocando dois instrumentos ao mesmo tempo e às vezes dividindo o instrumento tocado pela musicoterapeuta. Conseguia identificar os nomes das pessoas presentes, nomes dos instrumentos e suas cores. Seu corpo fez-se mais participativo nas sessões, mostrando-se mais atento e acompanhando o andamento musical com movimentos de braços, pernas, tronco e cabeça.

Foi possível observar o fortalecimento do vínculo terapêutico e a expansão da expressividade de Cadu, acompanhado de seu desenvolvimento musical. Adquiriu senso de conclusão musical, que se manifestava quando ele batia a palma de sua mão aberta na mão da musicoterapeuta no final de cada improvisação, sorrindo e estabelecendo contato visual. Durante as improvisações conduzidas, ele próprio já propunha novas possibilidades musicais para o Tema Clínico. Em relação ao seu desenvolvimento musical, destacamos: a percepção do pulso, a percepção de contrastes de intensidade e de andamento (principalmente o crescendo e o accelerando ao final da canção), sua própria sugestão de variação rítmica (nova subdivisão da célula rítmica principal), o acompanhamento de atividades musicais guiadas e o entendimento de frases musicais com pergunta e resposta. Os cantos com perguntas e respostas também permitiram que Cadu identificasse seu nome, o nome da musicoterapeuta e nomes de pessoas de seu convívio social. A seguir, nas Fig. 8 e 9, são apresentados dois exemplos de suas novas capacidades de expressão musical (subdivisão rítmica e pergunta/resposta).

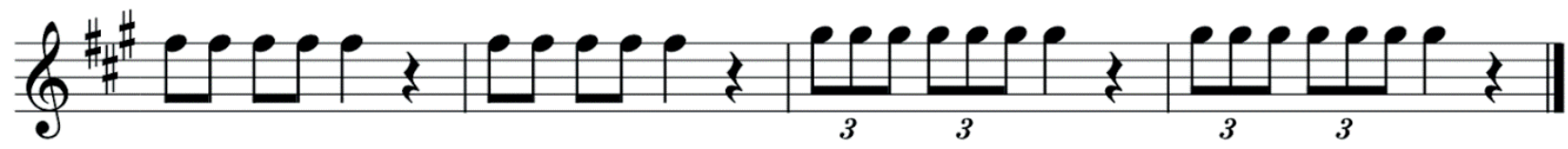

Fig. 8 - Exemplo de variação rítmica sugerida por Cadu

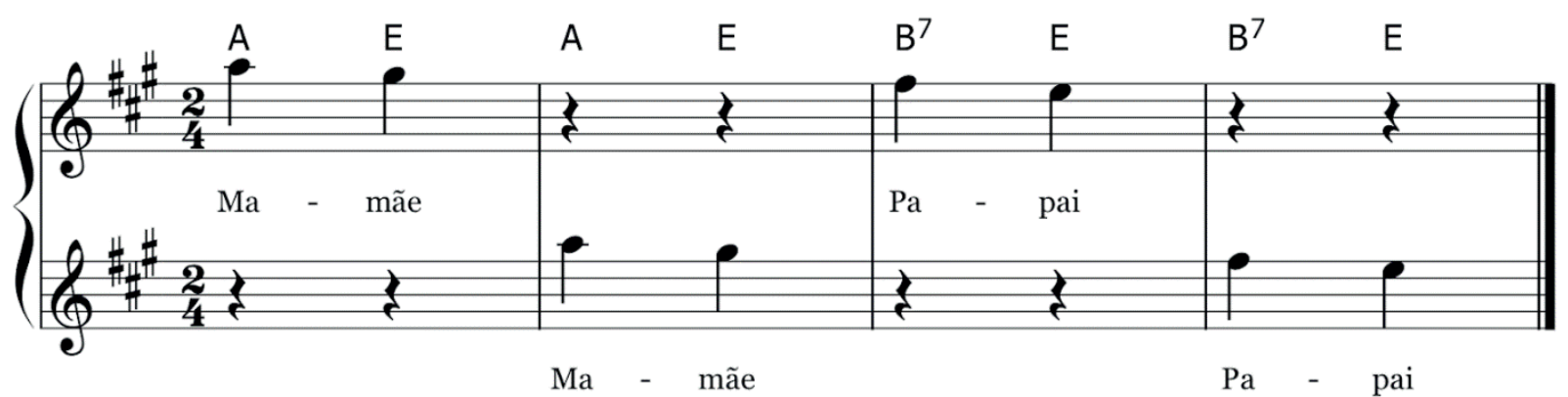

Fig. 9 - Exemplo de pergunta e resposta criada por paciente e musicoterapeuta 
Em um apanhado geral, percebemos que, na primeira etapa do processo musicoterapêutico, ocorreram contato, ambientação e exploração. A musicoterapeuta acolheu as iniciativas musicais do paciente (Fragmentos de Tema Clínico), ainda que rudimentares, e interveio musicalmente convidando-o a participar da atividade musical conjunta. Em um segundo momento, com o engajamento na experiência coativa, a musicoterapeuta sustentou a expressão musical do paciente e conduziu as improvisações para a criação de um Tema Clínico para as sessões, motivando a criança a continuar tocando junto e a expandir sua comunicabilidade musical. Na terceira e última etapa, musicoterapeuta e paciente propuseram variações do tema criado, mesmo que simples, porém dentro das capacidades musicais apresentadas por Cadu. Algumas variações foram incorporadas ao tema musical, ampliando-o e permitindo ampliação e assimilação de aquisições e habilidades intra e interpessoais exploradas pelo paciente.

\subsection{Ganhos musicais}

O desenvolvimento musical de Cadu pode ser percebido através do relato de seu processo musicoterapêutico e dos trechos musicais exemplificados acima. A fim de ratificar os resultados encontrados, foi realizada a análise de seus comportamentos musicais nas duas primeiras e nas duas últimas sessões, como pode ser observado em demonstrações na Tab. 1 e no Gráf. 1, a seguir.

\begin{tabular}{|c|c|c|c|c|c|c|c|}
\hline \multirow[b]{2}{*}{ Categorias } & \multirow[b]{2}{*}{ Padrões } & \multicolumn{3}{|c|}{ Primeiras sessões } & \multicolumn{3}{|c|}{ Últimas sessões } \\
\hline & & $\begin{array}{c}\text { Não } \\
\text { (2 pts.) }\end{array}$ & $\begin{array}{l}\text { Pouco } \\
\text { (1 pt.) }\end{array}$ & $\begin{array}{l}\text { Muito } \\
\text { (O pts.) }\end{array}$ & $\begin{array}{c}\text { Não } \\
(2 \text { pts.) }\end{array}$ & $\begin{array}{l}\text { Pouco } \\
\text { (1 pt.) }\end{array}$ & $\begin{array}{l}\text { Muito } \\
\text { (0 pts.) }\end{array}$ \\
\hline \multirow{7}{*}{$\begin{array}{l}\text { Comportamentos } \\
\text { restritivos }\end{array}$} & Estereotipias & & $x$ & & $x$ & & \\
\hline & Agressividade & $x$ & & & $x$ & & \\
\hline & Desinteresse & & $x$ & & $x$ & & \\
\hline & Passividade & & & $x$ & $x$ & & \\
\hline & Reclusão & & $x$ & & $x$ & & \\
\hline & Resistência & $x$ & & & $x$ & & \\
\hline & Pirraça & $x$ & & & $x$ & & \\
\hline & & $\begin{array}{c}\text { Não } \\
\text { (0 pts.) }\end{array}$ & $\begin{array}{l}\text { Pouco } \\
\text { (1 pt.) }\end{array}$ & $\begin{array}{l}\text { Muito } \\
(2 \text { pts.) }\end{array}$ & $\begin{array}{c}\text { Não } \\
(0 \text { pts.) }\end{array}$ & $\begin{array}{l}\text { Pouco } \\
\text { (1 pt.) }\end{array}$ & $\begin{array}{l}\text { Muito } \\
\text { (2 pts.) }\end{array}$ \\
\hline \multirow{5}{*}{ Socialização } & Contato visual & $x$ & & & & & $x$ \\
\hline & Comunicação verbal & $x$ & & & & $x$ & \\
\hline & Interação com objetos & & $x$ & & & $x$ & \\
\hline & Interação com instrumentos musicais & & $x$ & & & & $x$ \\
\hline & Interação com musicoterapeuta & & $x$ & & & & $x$ \\
\hline \multirow{3}{*}{ Cognição } & Atenção & & $x$ & & & & $x$ \\
\hline & Observação & & $x$ & & & & $x$ \\
\hline & Imitação & & $x$ & & & & $x$ \\
\hline
\end{tabular}




\begin{tabular}{|c|c|c|c|c|c|c|}
\hline \multirow{5}{*}{$\begin{array}{l}\text { Percepção/ } \\
\text { Exploração } \\
\text { rítmica }\end{array}$} & Pulso interno & & $x$ & & & $x$ \\
\hline & Regulação temporal & & $x$ & & & $x$ \\
\hline & Ritmo real & $x$ & & & & $x$ \\
\hline & Apoio & $x$ & & & & $x$ \\
\hline & Andamento & $x$ & & & $x$ & \\
\hline \multirow{7}{*}{$\begin{array}{l}\text { Percepção/ } \\
\text { Exploração } \\
\text { sonora }\end{array}$} & Som/silêncio & & $x$ & & & $x$ \\
\hline & Timbre & $x$ & & & & $x$ \\
\hline & Planos de altura & $x$ & & & $x$ & \\
\hline & Movimento sonoro & & $x$ & & & $x$ \\
\hline & Intensidade & $x$ & & & & $x$ \\
\hline & Repetição de ideias rítmicas e/ou melódicas & & X & & & $x$ \\
\hline & Senso de conclusão & $x$ & & & & $x$ \\
\hline \multirow{7}{*}{$\begin{array}{l}\text { Exploração } \\
\text { vocal }\end{array}$} & Vocalizações & & $x$ & & & $x$ \\
\hline & Balbucios & & $x$ & & & $x$ \\
\hline & Sílabas canônicas & & $x$ & & & $x$ \\
\hline & Imitação de fragmentos de canções & $x$ & & & $x$ & \\
\hline & Imitação de canções & $x$ & & & $x$ & \\
\hline & Criação de impulsos melódicos & $x$ & & & $x$ & \\
\hline & Criação vocal & & $x$ & & & $x$ \\
\hline \multirow{7}{*}{$\begin{array}{l}\text { Movimentação } \\
\text { corporal } \\
\text { (acompanhando } \\
\text { a música) }\end{array}$} & Andar & $x$ & & $x$ & & \\
\hline & Correr & $x$ & & $x$ & & \\
\hline & Parar & $x$ & & $x$ & & \\
\hline & Gesticular & & $x$ & & & $x$ \\
\hline & Dançar & $x$ & & $x$ & & \\
\hline & Movimentar & & $x$ & & & $x$ \\
\hline & Pular & $x$ & & $x$ & & \\
\hline
\end{tabular}

Tab. 1 - Escala de Desenvolvimento Musical de Cadu nas duas primeiras e nas duas últimas sessões. Todos os itens são mensurados de modo que a pontuação seja diretamente proporcional à melhora do paciente.

\section{Desenvolvimento musical de Cadu}

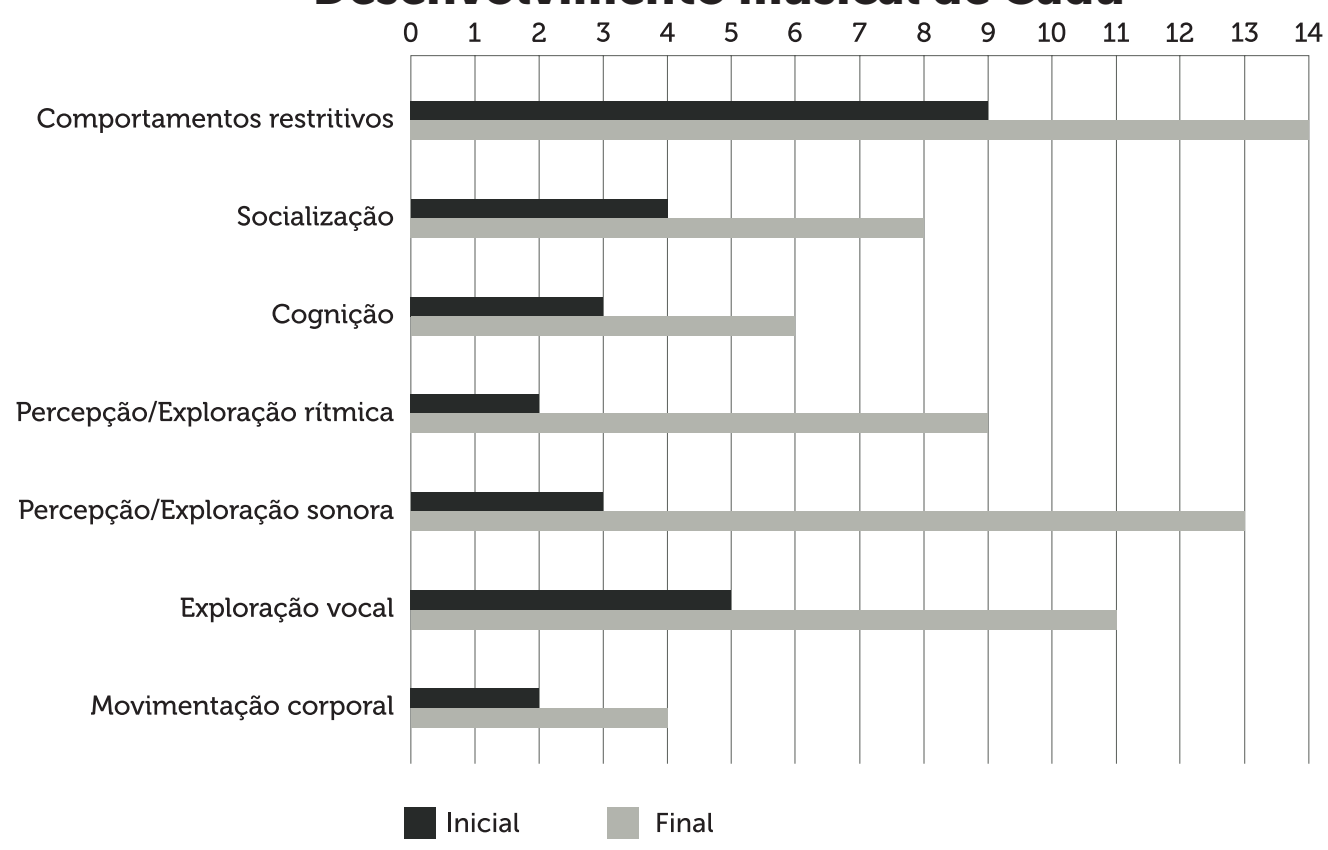

Gráf. 1 - Comparação entre avaliações inicial e final da Escala de Desenvolvimento Musical de Cadu 
A Tab. 1 e o Gráf. 1 nos permitem perceber que, para todos os itens da escala utilizada, Cadu apresenta-se nas últimas sessões na mesma pontuação ou em pontuação superior, demonstrando ganhos em todas as categorias avaliadas. Assim, ficou visível o desenvolvimento de comportamentos e habilidades musicais do paciente estudado, podendo-se destacar, por exemplo, a exploração das alterações de intensidade e andamento (percepção/exploração sonora e rítmica) e as imitações e criações vocais. A diminuição de comportamentos restritivos ajudou no aumento dos parâmetros de socialização (como o contato visual e a interação com a musicoterapeuta) e de percepção cognitiva (como a atenção e a imitação), que, por sua vez, auxiliam no aumento das possibilidades de o paciente perceber e explorar sons, ritmos e melodias em instrumentos musicais, no corpo e na voz.

Esses ganhos musicais também nos levam a refletir sobre a importância do Tema Clínico construído durante as sessões, decisivo para o desenrolar do processo musicoterapêutico aqui estudado (ilustrado na Fig. 6). A harmonia é simples (em sua maioria tríades e cadências puras), aproximando-se à percepção auditiva da criança com atraso no desenvolvimento (sem excesso de informações). Em contraposição ao espaço aberto dado pela modulação harmônica nos primeiros compassos, o ritmo não varia, apresentando sempre a célula rítmica dada ou o pulso. Assim, o Fragmento de Tema Clínico do paciente está sempre presente. Nesta primeira parte, as pausas abrem espaço para o novo, permitindo o jogo de imitação no canto (pergunta/resposta). Essa atividade estimulou a criança a aprender novas sílabas e novas palavras. A segunda parte representa a retomada da primeira célula rítmica tocada por Cadu - espaço seguro e de acolhimento do paciente, após o jogo de pergunta e resposta. Essa sessão permitiu as variações do Tema Clínico e o desenvolvimento da fala (com as propostas de variações de sílabas). Outro ponto importante desta segunda parte é a finalização em dominante com sétima, que tornou cíclico esse tema musical, convidativo para ser repetido, e permitiu atenção do paciente na retomada da experiência musical conjunta. As variações do tema propostas por Cadu permitiram que ele desenvolvesse autonomia na sua expressão de musicalidade ao longo da vivência musical. As variações na letra da música permitiram levar Cadu da fala silábica às palavras, até atingir o significado das mesmas.

Entende-se que os achados realçados neste relato de caso corroboram o alcance do desenvolvimento da musicalidade da criança no processo musicoterapêutico, que é um dos objetivos principais da Musicoterapia Improvisacional Musicocentrada, como defendido por seus precursores (NORDOFF; ROBBINS, 2007). Vale ressaltar aqui que essa visão do desenvolvimento da musicalidade de Cadu não seria possível se não a compreendêssemos como um aspecto natural de todo ser humano, conforme Queiroz (2003).

A experiência musical em Musicoterapia Improvisacional Musicocentrada busca ser sempre interativa e aprazível. De acordo com grandes nomes da Educação Musical, como Swanwick (1979), o desenvolvimento de habilidades musicais pode ser adquirido ao se proporcionar experiências musicais prazerosas, que têm maior foco na própria experiência de compor, ouvir e tocar do que na técnica. Compreendem-se aqui também as ideias apregoadas por Malloch (1999) e Trevarthen (1999) de que o caráter afetivo da música é determinante no estabelecimento e manutenção de vínculos sociais, comunicação e expressividade, que, por sua vez, influenciam no desenvolvimento da linguagem e da fala. 
As melhoras comportamentais de Cadu, como a interação social e a fala, serão evidenciadas na seção a seguir.

\subsection{Ganhos extramusicais}

Os dados coletados por meio da escala Autism Treatment Evaluation Checklist (ATEC) foram respondidos pela mãe, levando em consideração como Cadu se comportava fora das sessões de Musicoterapia, principalmente em casa e na escola, com adultos e com crianças da mesma idade. Segundo suas respostas, destacamos que, após o tratamento musicoterapêutico, Cadu passou a conseguir:

- atender a comandos simples,

- formar palavras, utilizando-as dentro de contexto comunicacional,

- manter diálogos simples,

- mostrar iniciativa na comunicação e na interação,

- manter contato visual,

- cumprimentar pessoas conhecidas ("oi" e "tchau"),

- imitar,

- brincar com crianças da sua idade,

- responder ao próprio nome,

- vestir-se sozinho e

- demonstrar imaginação.

Além disso,

- a apatia e a passividade de Cadu reduziram significativamente e

- as estereotipias que apresentava com as mãos foram cessadas por completo.

Todos esses itens estão contemplados nas subescalas do ATEC, e os totais de suas pontuações estão representados no gráfico a seguir.

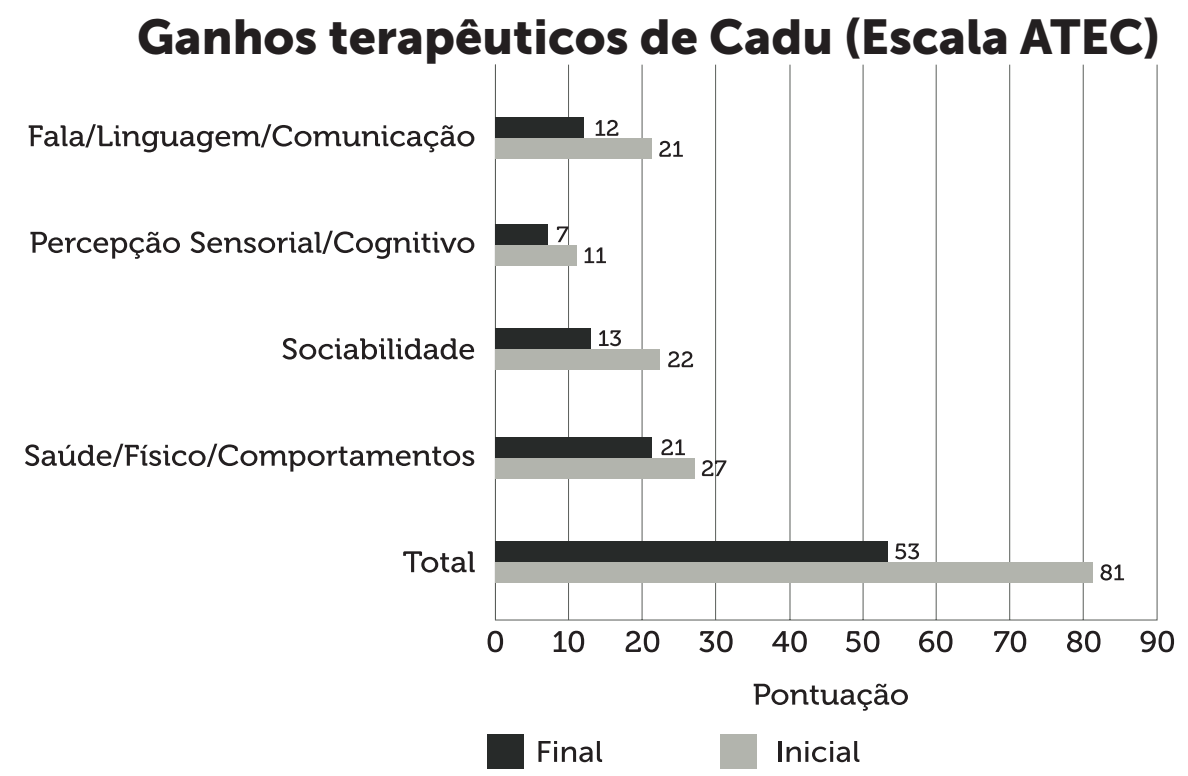

Gráf. 2 - Comparação entre avaliações inicial e final da escala Autism Treatment Evaluation Checklist

(Escala ATEC. As pontuações são inversamente proporcionais à melhora do paciente. 
É possível notar, pelo Gráf. 2, que houve melhoras nos sintomas autísticos de Cadu para todos os parâmetros avaliados pelo ATEC (fala, linguagem e comunicação; percepção sensorial e cognição; sociabilidade; saúde, aspectos físicos e comportamentos). Vale ressaltar que, ao contrário da Escala de Desenvolvimento Musical, a pontuação dessa escala é inversamente proporcional ao progresso da criança, apresentando valores menores na avaliação final para todas as subescalas e para o total da escala.

As respostas da mãe à escala ATEC mostraram, dentre outras coisas, melhoras em habilidades atencionais e sociais desempenhadas em contextos fora das sessões de Musicoterapia, que poderiam ser relacionadas às melhoras da atenção e interação vistas dentro das sessões, na Escala de Desenvolvimento Musical (Tab. 1). Assim, esses ganhos seriam entendidos como a ampliação e a generalização de repertórios de comportamentos da criança, tão discutidos e necessários para o TEA (BERGER, 2003; ROGERS; DAWSON, 2010). Outro aspecto importante notado tanto no ATEC como na Escala de Desenvolvimento Musical diz respeito ao aumento da capacidade de imitação de Cadu: sua melhora nessa capacidade pode sugerir aprimoramento das funções dos neurônios-espelho, tendo em vista que esse é um déficit comumente presente no TEA e que trocas musicais podem estimular esse sistema neuronal (MOLNAR-SZAKACS et al., 2009).

Uma vez que a Musicoterapia Improvisacional Musicocentrada trabalha com foco no desenvolvimento da musicalidade do paciente (NORDOFF; ROBBINS, 2007), entende-se que a aquisição progressiva de novas habilidades musicais foi, pouco a pouco, propiciando o desenvolvimento integral da criança estudada. Esta relação é visível principalmente nos comportamentos que são incentivados durante as experiências musicais, evidenciados nas variações do Tema Clínico de Cadu, como o desenvolvimento da linguagem (por exemplo, formação de palavras), o aumento de suas intenções comunicativas (por exemplo, cumprimentar pessoas conhecidas) e a melhora na qualidade das interações interpessoais (por exemplo, imitar, brincar e manter contato visual). Porém, ganhos terapêuticos também foram observados para outros comportamentos não diretamente relacionados ao fazer musical, como vestir-se sozinho, contribuindo para a integração na qualidade de diversas dimensões da vida da criança.

Esses achados contribuem para consolidar a Musicoterapia Improvisacional Musicocentrada como uma forma de tratamento capaz de oferecer o apoio terapêtico que, segundo estudiosos como Berger (2003) e Frith (2008), as crianças com TEA tanto precisam. Outros referenciais teóricos apresentados no presente trabalho também fundamentam de forma enfática este relato de caso: o fato de a primeira infância (na qual Cadu se encontrava) ser uma fase oportuna para o desenvolvimento cognitivo e social (FLOHR et al., 2000; ILARI, 2006) e como o contato com a música pode ter uma influência decisiva nesse desenvolvimento (TRAINOR; HANNON, 2013), especialmente nos casos de TEA (WIGRAM; GOLD, 2006; MOLNAR-SZAKACS; HEATON, 2012; SAMPAIO et al., 2015). 


\section{CONSIDERAÇÕES FINAIS}

Este artigo buscou elucidar teorias e práticas sobre os processos do desenvolvimento cognitivo-musical de crianças com Transtorno do Espectro do Autismo, levantando implicações importantes para as áreas envolvidas com TEA e música. O referencial teórico e o relato de caso apresentados contribuem para percebermos que os ganhos terapêuticos das crianças com TEA que passam por processo musicoterapêutico podem caminhar lado a lado com o desenvolvimento musical da criança, um servindo de estímulo para o outro.

O tema ainda traz muitas possibilidades de ser explorado, podendo ser aprofundado em outros focos teóricos em estudos posteriores. Como exemplo de continuidade das investigações, apontamos que a Escala de Desenvolvimento Musical aplicada neste estudo está em processo de validação conduzido pelo presente grupo de pesquisa, para que possa ser utilizada por outros pesquisadores e profissionais, especialmente musicoterapeutas e educadores musicais que trabalham com crianças com TEA. Uma ferramenta de avaliação padronizada e reaplicável faz-se necessária para pesquisas sobre o desenvolvimento musical e auxílio à observação das evoluções de pessoas com esse diagnóstico.

As intervenções musicoterapêuticas apresentadas no relato de caso também podem auxiliar nas reflexões sobre atitudes e formas de intervenções de outros profissionais com crianças com Transtorno do Espectro do Autismo. Na Musicoterapia Improvisacional Musicocentrada, ao indicar o desenvolvimento musical de crianças com TEA como um dos objetivos da intervenção, torna-se mais importante o aprimoramento da expressão da musicalidade do indivíduo do que a aquisição de habilidades técnicas. Dessa forma, o engajamento na experiência musical coativa faz-se essencial para seu desenvolvimento integral. Quando a criança consegue expandir suas experiências musicais, também é capaz de encontrar novas possibilidades de ser no mundo e dentro de si.

\section{AGRADECIMENTOS}

Os autores agradecem ao Prof. Dr. Arthur Kummer por ter cedido os vídeos dos atendimentos realizados na pesquisa de mestrado "Efeitos da Musicoterapia Improvisacional no tratamento de crianças pré-escolares com autismo" (Programa de Pós-Graduação em Neurociências, ICB/UFMG) para o presente grupo de pesquisa.

\section{REFERËNCIAS}

AMERICAN PSYCHIATRIC ASSOCIATION (APA). Diagnostic and statistical manual of mental disorders (DSM-5). Arlington: American Psychiatric Publishing, 2014.

AVILA, D. C. A musicalidade comunicativa das canções: um estudo sobre a identidade sonora de crianças com autismo. 2016. 248 f. Tese (Doutorado em Psicologia Escolar e do Desenvolvimento Humano) - Instituto de Psicologia, Universidade de São Paulo, São Paulo, 2016. 
BERGER, D. S. Music Therapy, Sensory Integration and the Autistic child. London, UK: Jessica Kingsley Publishers Ltd, 2003.

BOSO, M.; EMANUELE, E.; MINAZZI, V.; ABBAMONTE, M.; POLITI, P. Effect of Long-Term Interactive Music Therapy on Behavior Profile and Musical Skills in Young Adults with Severe Autism. The Journal of Alternative and Complementary Medicine, v. 13, n. 7, p. 709-712, 2007. DOI: 10.1089/acm.2006.6334.

BRANDALISE, A. Musicoterapia músico-centrada: Linda - 120 sessões. São Paulo: Apontamentos, 2001.

BROWNELL, M. D. Musically Adapted Social Stories to Modify Behaviors in Students with Autism: Four Case Studies. Journal of Music Therapy, v. 39, n. 2, p. 117-144, 2002.

BRUSCIA, K. Improvisational Models of Music Therapy. Springfiled, IL: Charles C. Thomas Publishers, 1987.

CHAGAS, M.; PEDRO, R. Musicoterapia: desafios entre a modernidade e a contemporaneidade - como sofrem os híbridos e como se divertem. Rio de Janeiro: Mauad X Bapera, 2008.

FABRICIUS, T. On neural systems for speech and song in autism. Letter to the editor. Brain, v. 135, n. 11, p. 222, 2012. DOI: 10.1093/brain/aws179.

FIGUEIRA, B. R. M. O percurso histórico do pensamento científico sobre as emoções musicais. In: ARAÚJO, R. C.; RAMOS, D. (Orgs.). Estudos sobre a motivação e emoção em cognição musical. Curitiba: Editora UFPR, 2015, p. 59-94.

FLOHR, J.; MILLER, D. C.; DEBESU, R. EEG studies with young children. Music Educators Journal, v. 87, p. 28-32, 2000.

FREIRE, M. H. Efeitos da Musicoterapia Improvisacional no Tratamento de Crianças com TEA. 2014. 74f. Dissertação (Mestrado em Neurociências) - Universidade Federal de Minas Gerais, UFMG, Belo Horizonte, 2014.

FREIRE, M.; PARIZZI, B. As relações dos efeitos terapêuticos da Musicoterapia Improvisacional e o desenvolvimento musical de crianças com autismo. Revista Nupeart, v. 14, p. 46-55, 2015.

FREIRE, R. Memória e Imitação na Percepção Musical. In: SIMPÓSIO INTERNACIONAL DE COGNIÇÃO E ARTES MUSICAIS, 6, 2010, Rio de Janeiro. Anais... Rio de Janeiro: UFRJ, 2010.

FRITH, U. Autism: a very short introduction. Oxford: University Press, 2008. 
GATTINO, G. Musicoterapia aplicada à avaliação da comunicação não verbal de crianças com transtornos do espectro autista: revisão sistemática e estudo de validação. 2012. 180f. Tese (Doutorado em Medicina) - Universidade Federal do Rio Grande do Sul, Porto Alegre, 2012.

GEMBRIS, H. Historical phases in the definition of musicality. Psychomusicology: A Journal of Research in Music Cognition, v. 16, n.1-2, p.17-25, 1997.

GERLING, C.C., SANTOS, R.A.T. As conexões entre música e emoção sob perspectivas psicológicas, filosóficas e estéticas. In: ARAÚJO, R. C.; RAMOS, D. (Orgs.). Estudos sobre motivação e emoção em cognição musical. Curitiba: Editora UFPR, 2015, p.13-44.

ILARI, B. S. Desenvolvimento cognitivo-musical no primeiro ano de vida. In: ILARI, B. S (Org.). Em busca da mente musical: ensaios sobre os processos cognitivos em música - da percepção à produção musical. Curitiba: UFPR, 2006, p. 271-302.

JUSLIN, P. N.; SLOBODA, J. A. (Eds.). Music and Emotion: Theory and Research. New York: Oxford University Press, 2001.

KIM, J.; WIGRAN, T.; GOLD, C. The Effects of Improvisational Music Therapy on Joint Attention Behaviors in Autistic Children: A Randomized Controlled Study. Journal Autism Dev Disord, v. 38, p. 1758-1766, 2008. DOI: 10.1007/s10803-008-0566-6.

KIM, J.; WIGRAN, T.; GOLD, C. Emotional, motivational and interpersonal responsiveness of children with autism in improvisational music therapy. Autism SAGE Publications and The National Autistic Society, v. 13, n. 4. p. 389-409, 2009. DOI: 10.1177/1362361309105660.

KIRKLAND, K. International Dictionary of Music Therapy. New York: Routledge, 2013. p.81.

KRATUS, John. A developmental study of children's interpretation of emotion in music. Psychology of Music, v.21, n.1, p 3-19, 1993.

MAFFIOLETTI, L.A. Musicalidade comunicativa e senso de eu. Orfeu, v.2, n.2, p. 133-146, 2017.

MALLOCH, S. Mothers and Infants and communicative musicality. Musicae Scientiae, v.3, n.1, p. 29-57, 1999.

MENDONÇA, J. E. A musicalidade comunicativa em processos de construção de conhecimento de crianças de seis anos. 2015. $182 \mathrm{f}$. Tese (Doutorado em Processos de Desenvolvimento Humano e Saúde) - Universidade de Brasília, Brasília, 2015.

MOLNAR-SZAKACS, I.; HEATON, P. Music: a unique window into the world of autism. 
Annals of New York Academic Science, n. 1252, p. 318-324, 2012. DOI: 10.1111/j.17496632.2012.06465.x.

MOLNAR-SZAKACS, I; WANG, M. J.; LAUGESON, E. A., OVER, K., WU, W. L.; PIGGOT, J. Autism, Emotion Recognition and the Mirror Neuron System: The Case of Music. Mcgill Journal of Medicine, n. 12, v. 2, p. 87-98, 2009.

NORDOFF, P.; ROBBINS, C. Music Therapy in Special Education. London: MacDonald \& Evans, 1975.

NORDOFF, P.; ROBBINS, C. Creative Music Therapy: a guide to fostering clinical musicianship. 2. ed. Gilsum: Barcelona Publishers, 2007.

OLIVEIRA, G. C. Desenvolvimento musical de crianças autistas em diferentes contextos de aprendizagem: um estudo exploratório. 2015. 135 f. Dissertação (Mestrado em Educação Musical) - Escola de Música, Universidade Federal de Minas Gerais, Belo Horizonte, 2015.

OUIMET, T.; FOSTER, N. E. V.; TRYFON, A.; HYDE, K. L. Auditory-musical processing in autism spectrum disorders: a review of behavioral and brain imaging studies. Annals of New York Academic Science, n. 1252, p. 325-331, 2012. DOI: 10.1111/j.17496632.2012.06453.x.

PEDERIVA, P. Musicalidade, fala expressão das emoções. In: SIMPÓSIO INTERNACIONAL DE COGNIÇÃO E ARTES MUSICAIS, 4, 2008, São Paulo. Anais... São Paulo: USP, 2008. 01 CD-ROM.

PIEDADE, A. T. C. O ouvido popular: notas sobre o relativismo da musicalidade. In: SIMPÓSIO INTERNACIONAL DE COGNIÇÃO E ARTES MUSICAIS, 1, 2006, Curitiba. Anais... Curitiba: Deartes UFPR, 2006, p. 177-183.

QUEIROZ, G. J. P. Aspectos da Musicalidade e da Música de Paul Nordoff e suas implicações na prática clínica musicoterapêutica. São Paulo: Apontamentos Editora, 2003.

RIMLAND, B.; EDELSON, S. M. Autism is Treatable (US): Autism Treatment Evaluation Checklist (ATEC). San Diego, CA: Autism Research Institute (ARI), 2007. Disponível em: <http://www.autism.com/ind_atec>. Acesso em: 19 abr 2009.

ROCHA, V. C.; BOGGIO, P. S. A música por uma óptica neurocientífica. PerMusi, n. 27, p. 132-140, 2013. 
ROGERS, S. J.; DAWSON, G. Intervenção Precoce em Crianças com Autismo. Lisboa: Lindel - Edições Técnicas. 2010.

SACKS, O. Alucinações Musicais. São Paulo: Cia. das Letras, 2007.

SAMPAIO, R. T.; LOUREIRO, C. M. V.; GOMES, C. M. A. A Musicoterapia e o Transtorno do Espectro do Autismo: uma abordagem informada pelas neurociências para a prática clínica. PerMusi, Belo Horizonte, n. 32, p. 137-170, 2015. DOI: 10.1590/permusi2015b3205.

SANTOS, C. E. C. "Desenvolvimento de habilidades musicais em crianças autistas": um projeto de extensão, pesquisa e ensino. Nupeart, v. 14, p. 74-90, 2015.

SARAPA, K. B.; KATUSIC, A. H. Application of music therapy in children with autistic spectrum disorder/Primjena muzikoterapije kod djece s poremecajem iz autisticnog spektra. Revija za Rehabilitacijska Istrazivanja, v. 48, n. 2, p. 124-129, 2012.

SWANWICK, K. The parameters of music education. In: SWANWICK, K (Ed.) A Basis for Music Education. London: Routledge, 1979, p 40-53.

THOMPSON, G. A.; MCFERRAN, K. S.; GOLD, C. Family-centred music therapy to promote social engagement in young children with severe autism spectrum disorder: a randomized controlled study. Child: Care Health Development, v. 40, n. 6, p. 840-852, 2013. DOI: $10.1111 /$ cch.12121.

TRAINOR, L. J.; HANNON, E. E. Musical Development. In: DEUTSCH, D. (Ed.). The Psychology of Music. 3. ed. San Diego, CA: Elsevier, 2013, p. 423-497.

TREVARTHEN, C. Musicality and the intrinsic motive pulse: evidence from psychobiology and infant communication. Musicae Scientia, v. 3, n. 1, p. 155-215, 1999.

WAN, C.; SCHLAUG, G. Neural pathways for language in autism: the potential for music based treatments. Future Neurology, v. 5, n. 6, p. 797-805, 2010.

WIGRAM, T.; GOLD, C. Music therapy in the assessment and treatment of autistic spectrum disorder: clinical application and research evidence. Child: Care Health Development, v. 32, n. 5, p. 535-542, 2006.

WORLD FEDERATION OF MUSIC THERAPY (WFMT). What is Music Therapy?. Montreal, 2011. Disponível em: <http://www.wfmt.info/wp-content/uploads/2014/05/ENGLISH-NEW-What-is-music-therapy.pdf>. Acessado em: 05/07/2018. 